\title{
AN INTEGRATED, ANIMATED MODEL OF THE (NA, K)-ATPase HYDROLYTIC CYCLE.
}

\author{
Leone, F.A.; Furriel, R.P.M.; ${ }^{1}$ McNamara ${ }^{1}$, J.C.; Borin, I.A. and ${ }^{2}$ Horisberger, J.D.
}

Departamento de Química - FFCLRP/USP, 'Departamento de Biologia - FFCLRP/USP. 14040-901 Ribeirão Preto, SP; and ${ }^{2}$ Department of Physiology and Toxicology/University of Lausanne. CH 1005, Switzerland.

The ( $\mathrm{Na}, \mathrm{K})$-ATPase, or sodium pump, is the principal, active transport system that establishes sodium and potassium gradients across the plasma membranes of all animal cells. Such gradients are critical to sustaining important cellular functions like osmotic equilibrium, cell volume and $\mathrm{pH}$ homeostasis, among many others (Ann Rev Physiol 65: 817, 2003; Physiol 19: 377, 2004). This transport protein is a heterodimer that consists of a 110-kDa $\alpha$ subunit and a $55-\mathrm{kDa}$, glycosylated $\beta$-subunit. A group of seven small proteins, known as FXYD proteins from the sequence of a conserved motif has been identified recently, and one of these, FXYD2, constitutes the ( $\mathrm{Na}, \mathrm{K}$ )ATPase $\gamma$-subunit. Our model is based on conformational changes occurring between the E1 and E2 forms of the enzyme, which initiates its hydrolytic cycle at a high ATP/ADP ratio. While all steps are reversible, the model does not include the reverse reactions that can take place under appropriate conditions. The E1 state corresponds to that of the SERCA, recently crystallized (Science 304; 1672, 2004; Nature 430: 529, 2004). The animation was developed in Macromedia Flash $8.0^{\circledR}$ and illustrates the principle of an alternating-access model of an ion pump. The protein is embedded in the membrane with the extracellular face uppermost and the cytoplasmic face at the bottom. Access from the cytoplasmic or extracellular faces to the cation-binding sites, located in the transmembrane moiety, are controlled by two gates (moving horizontal bars), and conformations showing the two gates closed correspond to states with occluded $\mathrm{Na}^{+}$and $\mathrm{K}^{+}$sites. Changes in cation-binding site structure entail selective modifications of cation affinity. As the animation proceeds, the mechanism revealing the different steps of enzyme activity can be accessed through a pop-up window. A key explaining the different animation elements is also provided.

Supported by: FAPESP, CNPq, and CAPES 